\title{
PENDAMPINGAN PENILAIAN KINERJA USAHA KERAJINAN DI PINANG KOTA TANGERANG
}

\author{
Arifin Djakasaputra ${ }^{1}$, Ardiansyah ${ }^{2}$, dan Maswar Abdi ${ }^{3}$ \\ ${ }^{1}$ Jurusan Manajemen Fakultas Ekonomi dan Bisnis, Universitas Tarumanagara Jakarta \\ Email: arifind@fe.untar.ac.id \\ ${ }^{2}$ Jurusan Akuntansi Fakultas Ekonomi dan Bisnis, Universitas Tarumanagara Jakarta \\ Email: ardiansyah@fe.untar.ac.id \\ ${ }^{3}$ Jurusan Manjemen Fakultas Ekonomi dan Bisnis, Universitas Tarumanagara Jakarta \\ Email: maswara@fe.untar.ac.id
}

\begin{abstract}
The objective of the activity is to provide assistance to recycling handicraft businesses in Tangerang in assessing business performance. Through provision of knowledge on how to assess business performance and assistance in assessing the performance of businesses that have been running so far. This activity refers to the results of the research grant from the Directorate General of Higher Education as a team member, regarding the IKM business performance appraisal instrument is very necessary in running a business. in order to build a competitive advantage. The activity is carried out at the Lumintu business group, which employs the elderly to make plaits in Sudimara Pinang, Tangerang City. Based on the analysis of partner problems, there is still weak knowledge of performance appraisals so that they have not been able to achieve competitive advantage. The method offered in this activity is to implement a performance appraisal instrument in the form of socialization and assistance to Lumintu business owners. Through socialization about performance appraisal. Partners are very enthusiastic in listening to the material that has been delivered, and there is two-way communication between partners and the team. Furthermore, the assistance assesses the performance. Overall, the business performance is considered adequate. There are several things that need to be improved, such as the internal performance in the aspect of human resources and finansial.It is quite difficult for partners to retain the elderly to continue making weaving. For that we need continuous motivation to remain productive.
\end{abstract}

Keyword: performance appraisal, outreach, mentoring, IKM LUMINTU

\begin{abstract}
ABSTRAK
Tujuan kegiatan adalah melakukan pendampingan pada usaha kerajinan daur ulang di Tangerang dalam menilai kinerja usaha. Melalui pembekalan pengetahuan tentang cara menilai kinerja usaha dan pendampingan menilai kinerja usaha yang selama ini telah dijalankan. Kegiatan ini mengacu dari hasil penelitian hibah dikti sebagai anggota tim, tentang instrumen penilaian kinerja usaha IKM sangatlah diperlukan dalam menjalankan usaha. agar dapat membangun keunggulan bersaing. Kegiatan dilakukan pada kelompok usaha Lumintu yang memperkerjakan para lansia membuat anyaman di Sudimara Pinang Kota Tangerang. Bedasarkan analisis masalah mitra, masih lemahnya pengetahuan akan penilaian kinerja sehingga belum mampu mencapai keunggulan bersaing. Metode yang ditawarkan pada kegiatan ini adalah mengimplementasikan instrumen penilaian kinerja dalam bentuk sosialisasi dan pendampingan kepada pemilik usaha Lumintu. Melalui sosialisasi tentang penilaian kinerja. Mitra sangat antusias dalam mendengarkan materi yang telah disampaikan, dan terjadinya komunikasi dua arah antara mitra dengan tim. Selanjutnya pendampingan menilai kinerja. Secara keseluruhan kinerja usaha dinilai cukup. Ada beberapa hal yang harus diperbaiki seperti pada kinerja internal di aspek SDM dan keuangan. Cukup sulit bagi mitra mempertahankan para lansia untuk terus lanjut membuat anyaman. Untuk itu perlu motivasi secara terus menerus untuk tetap menjadi produktif.
\end{abstract}

Kata kunci: penilaian kinerja, sosialisasi, pendampingan, IKM LUMINTU

\section{PENDAHULUAN}

Saat ini perkembangan bisnis sudah semakin kompetitif. Pebisnis tidak hanya menghadapi kompetitor lokal tetapi juga Internasional. Kondisi tersebut mengharuskan organisasi melakukan perubahan-perubahan. Banyak organisasi atau pebisnis dengan bermacam macam skala usaha, telah melakukan restrukturisasi dan mempersiapkan diri menjadi lebih profesional, berorientasi pada model bisnis yang berkompetitif Nandakumar et al., (2010). Mengacu hasil penelitian sebelumnya tentang instrumen penilaian kinerja. Banyak instrumen yang dibuat para akademisi dan praktisi, dan instrumen tersebut mampu memotret kinerja perusahanaan secara keseluruhan. 
Tiga di antaranya adalah: Balanced Scorecard Kaplan dan Norton,(2005), Integrated Performance Measurement System (IPMS) Bititci et al, (1997), dan SMART System dari Wang Laboratory, Inc. Usaha IKM kecil menengah membutuhkan sistem pengukuran kinerja sederhana, terfokus, jelas dan berguna (Laitinen 1996,). Untuk itu model pengukuran yang digunakan pada UKM lebih disederhanakan.

Neely (1999) menawarkan rerangka kerja kinerja, "prisma kinerja", disebut sebagai "sentral stakeholder". Miles et al (2000), pengukuran kinerja secara subjektif lebih digunakan dari pada pengukuran obyektif. Beal (2000) mengemukakan bahwa belum ada konsensus tentang ukuran kinerja yang paling layak, ukuran-ukuran kinerja yang selama ini dipakai dalam banyak penelitian masih banyak kekurangan, belum adanya konsensus tentang ukuran kinerja. Untuk itu dimungkinkan menggunakan ukuran subyektif, yang mendasarkan pada persepsi manajer. Zahra and Das (1993) membuktikan bahwa ukuran kinerja subyektif memiliki tingkat reliabilitas dan validitas yang tinggi. Pengukuran kinerja dapat berdasarkan pada persepsi manajer, hasil penelitian Munizu (2010) menunjukkan adanya aspek internal perusahaan yang meliputi: SDM, finansial, teknis dan opersional, pasar dan pemasaran. Selanjutnya aspek eksternal yang meliputi persepsi pemerintah, pemasok, pesaing dan konsumen.

Kegiatan PKM ini mengacu pada instrumen penilaian kinerja dari hasil penelitian di atas , dan hasil penelitian anggota tim pada tahun 2019, yang telah mengidentifikasi sebanyak 19 faktor internal dan 31 eksternal penting dalam menilai kinerja usaha kecil menengah.Untuk implementasi dari hasil penelitian anggota tim perlu melakukan kegiatan PKM. Mitra yang menjadi tempat kegiatan adalah usaha kecil menengah yang bergerak dalam bidang industri kreatif daur ulang/ IKM Lumintu, berdomisili di kecamatan Sudimara Pinang kota Tangerang. Sudah melakukan usaha daur ulang sejak tahun 1998,memperkerjakan kaum lansia dan ibu ibu rumah tangga. Berdasarkan hasil observasi awal,usaha yang dijalankan mitra belum mencapai kinerja yang baik, akibat dari belum memiliki pengetahuan tentang cara menilai kinerja usaha. Oleh karena itu Tim PKM perlu membekali mitra tentang pengetahuan kinerja dan melakukan pendampingan dalam menilai sejauhmana capaian dari kinerja usaha yang sudah memenuhi dan yang belum terpenuhi bagi IKM dalam menjalankan usaha.

\section{METODE PELAKSAAN PKM}

Berdasarkan permasalahan yang dihadapi IKM Lumintu, solusi yang ditawarkan berupa, membuat materi penilaian kinerja sosialisasi, dan pendampingan.

1. Kegiatan sosialisasi. Dilakukan untuk memberikan pembekalan pengetahuan dalam penilaian kinerja. Untuk melaksanakan kegiatan sosialisasi ini, ada beberapa langkah yang perlu dilakukan.

a. Tim PKM sebagai tutor menghubungi pihak terkait, yaitu pemilik IKM Lumintu untuk minta ijin melakukan sosialisasi.

b. Tim PKM sebagi tutor berkoordinasi dengan pemilik, agar dapat memberikan jadwal untuk melakukan kegiatan sosialisasi.

c. Tim PKM sebagai tutor menyampaikan materi sosialisasi melalui ceramah, diskusi, dan tanya jawab. sosialisasi secara daring

d. Tutor mejelaskan tentang factor internal dan eksternal dalam melakukan penilaian kinerja.

e. Pemilik IKM Lumintu dalam hal ini bapak Slamet Riyadi sebagai ketua mendengarkan dan memberikan respon pada tim PKM atas materi sosialisasi.

2. Pendampingan. Kegiatan pendampingan dilakukan melalui Langkah-Langkah sebagai berikut:

a. Tim membuat mengecek kinerja yang sudah dimiliki 
b. Tim melakukan mengidentifikasi kinerja internal dan eksternal

c. Tim melakukan capaian kinerja yang sudah dilakukan

d. Tim memberikan masukan capaian kinerja

e. Tim menyampaikan pilihan strategi penilaian kinerja yang sudah sesuai dan belum

f. Tim melakukan pendampingan menyusun kinerja usaha IKM

g. Tim Melakukan perbaikan pada kinerja yang harus diperbaiki /belum sesuai

h. Tim memberikan solusi untuk permasalahan yang ada, memperbaiki dan meningkatkan kinerja yang sudah baik.

i. Tim menyerahkan hasil penilaian kinerja sebagai dasar evaluasi dalam meningkatkan produktivitas kerja IKM

\section{HASIL DAN PEMBAHASAN}

Mitra yang menjadi fokus kegiatan bergerak dalam bidang usaha Tas Anyaman dari Aluminium Foil, bernama Slamet Riyadi, pengusaha anyaman di kawasan Sudimara Pinang, Tangerang dibantu oleh anak -anak nya. Mendirikan usaha sejak tahun1998. Usaha ini diberi nama Tas Anyaman Lumintu. Singkatan dari lumayan itung-itung nunggu tutupnya umur. Pondok Kreasi Daur Ulang Lumintu ini merekrut masyarakat sekitar yang sudah lanjut usia. Saat ini yang sudah bergabung, untuk lansia sekitar 30 orang dengan usia 50 sampai 80 tahun, dan 10 ibu rumah tangga. Bahan baku yang digunakan adalah limbah pabrik berupa aluminium foil dari kemasan pasta gigi , limbah kain, plastik, maupun almunium bahan-bahan baku dari limbah pabrik yang tidak terpakai untuk dibuat menjadi kerajinan anyaman. Limbah pabrik ini biasa berupa lembaran aluminium foil berukuran satu meter hingga tiga meter. Kemudian, bahan tersebut disambung dengan isolasi agar merekat lebih kuat. Hingga akhirnya melewati proses penyisiran dan pemotongan. Aluminium foil tersebut nantinya dipotong sesuai dengan kebutuhan. "Ukuran 60 sentimeter bisa untuk membuat tempat pensil atau dompet kecil,". Sedangkan untuk membuat tas anyaman diperlukan 1,5 meter hingga 1,8 meter aluminium foil. Untuk pengerjaannya akan diserahkan kepada ibu-ibu lansia. Setiap proses pengerjaan bisa menghasilkan sekitar 30 jenis kerajinan anyaman, di antaranya : tas wanita, tas seminar, koper, dan travelling bag, tikar, sajadah. Dengan kisaran harga dari 30 ribu rupiah hingga 400 ribu rupiah. Produk yang dihasilkan mitra dapat dilihat pada Gambar 1.

Selain melakukan usaha di rumah, sebagai tempat produksi. Pak Slamet dan mbak Aulia juga sering diundang untuk work shop ke Sekolah-Sekolah Internasional.

\section{Membuat Model Penilaian Kinerja Untuk Kelompok IKM}

Output pertama dirancang dalam kegiatan PKM adalah membuat panduan strategi Penilaian kinerja usaha IKM . Desain ini bertujuan untuk memberikan pemahaman agar pemilik usaha IKM memiliki pengetahuan akan dalam melakukan penilaian atas hasil usaha eceran secara lebih baik, dan dapat menghadapi pesaing. Penyusunan draf panduan dilakukan dengan cara diskusi, membaca buku literatur, bertanya dengan pakar dan melalui hasil penelitian. Model tersebut divisualisasikan dalam bentuk sosialisasi kepada komunitas usaha IKM di Usaha Lumintu Sudimara Jombang Tangerang Selatan melalui ZOOM.. Spesifikasi model penilaian yang berorientasi pada kondisi internal dan eksternal. Adapun model penilaian kinerja aspek internal tergambar dalam suatu piramida bagan 1dan 2 seperti pada Gambar 2. Rodhiah dan Zahrida (2016) International Conference -ICONLEE) 


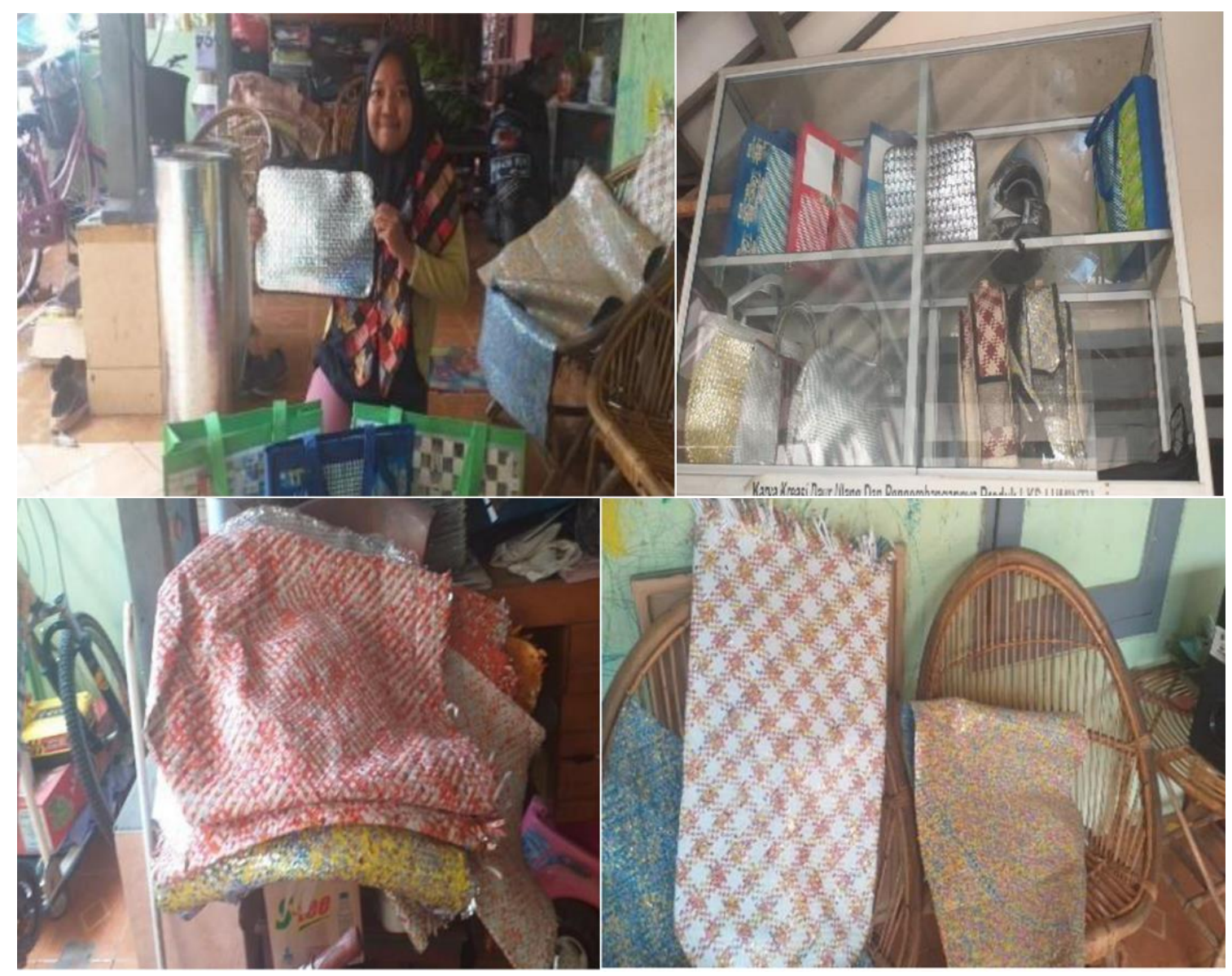

Gambar 1. Produk IKM Lumintu

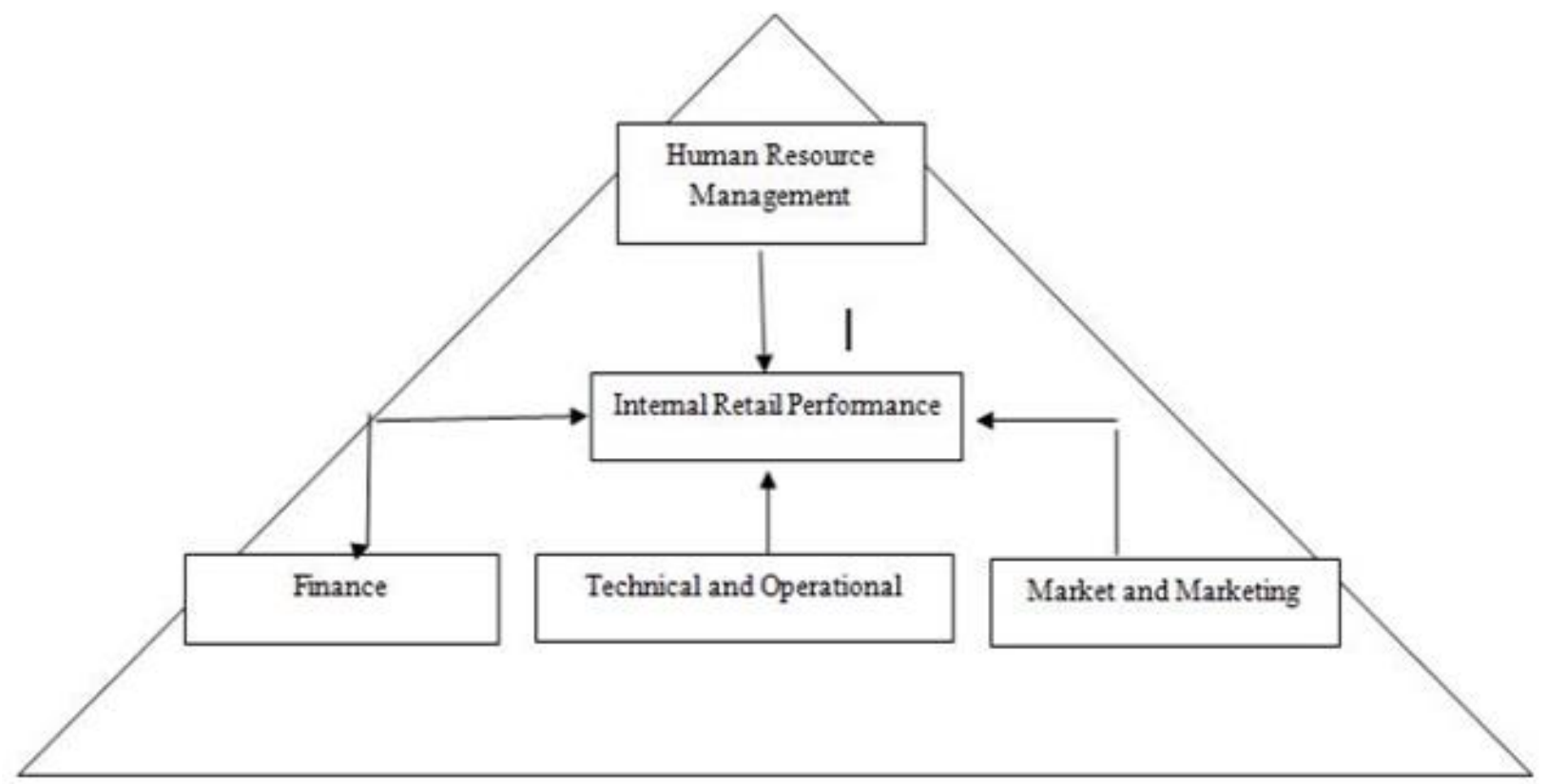

Gambar 2. Pengembangan Model Penilaian Kinerja Faktor Internal

Nelly (1999) menawarkan rerangka kerja kinerja, "prisma kinerja", disebut sebagai "sentral stakeholder". Rerangka kinerja ini mempertimbangkan dahulu keinginan dan kebutuhan semua pemangku kepentingan di perusahaan (karyawan, pelanggan, pemasok, rekan kerja, penengah), strategi diperoleh dari penilaian 
yang berhubungan dengan keinginan dan kebutuhan pemangku kepentingan Untuk itu instrumen yang akan diukur disajikan dalam Gambar 3.

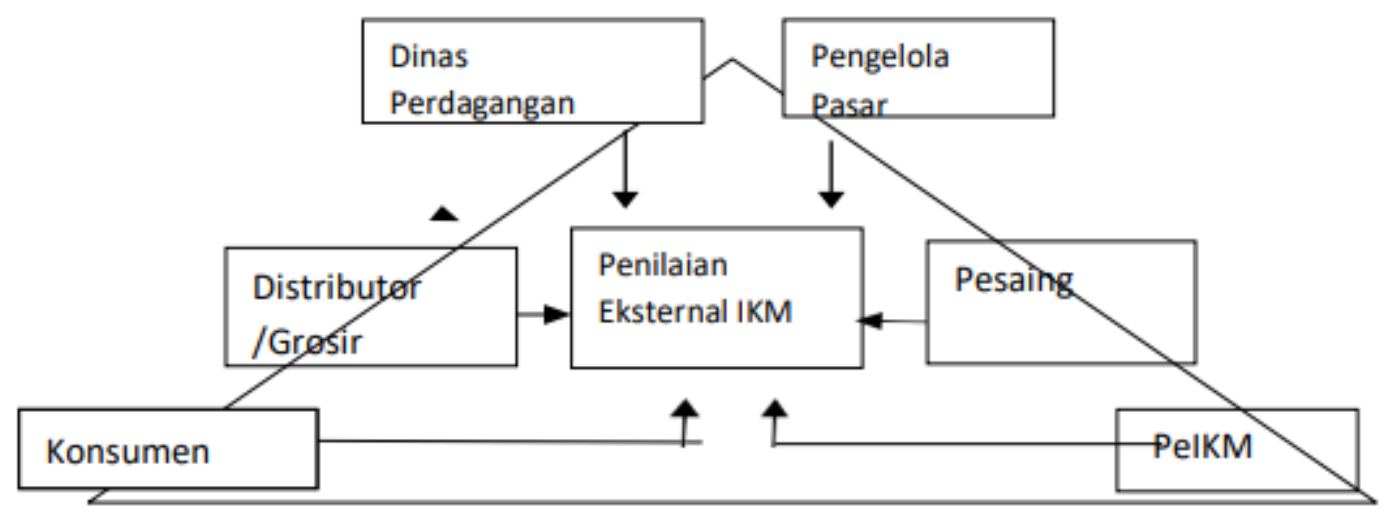

Gambar 3. Pengembangan Model Penilaian Faktor Eksternal

\section{Mensosialisasikan Metode Penilaian Kinerja}

Proses FDG dilakukan juga pada pembuatan model penilaian baik dari internal dan eksternal. Melalui berbagai instrumen penilaian kinerja IKM akan dapat mengetahui lebih jauh, mana kinerja usaha yang masih kurang, dan mempertahankan kinerja yang dianggap mampu membentuk keunggulan bersaing. Spesifikasi materi pelatihan berupa pemahaman dalam melakukan penilaian kinerja seperti yang ada pada tabel 1 dan 2 di atas. Sebagai Contoh " pada Usaha Lumintu", dapat dilihat kondisi dari tiap tahapan yang dimiliki dan perlu disosialisasikan untuk melakukan perbaikan pada tahapan yang masih memiliki kelemahan. Levy,2012 mengemukakan keterlibatan anggota organisasi sangat mendukung kesuksesan usaha IKM dan pada akhirnya memberikan efek pada kinerja IKM. Untuk itu berbagai kebijakan-kebijakan yang dapat dijadikan sumber penilaian dalam strategi organiasi ini dapat dikelompokkan dalam hal; Dukungan diantara personil organisasi, saling kerja sama, kemauan memberikan penjelasan dan kemampuan personil organisasi. Pendekatan memperkenalkan panduan tersebut dengan cara sosialisasi dan komunikasi secara aktif dengan metode forum discusion group (FDG) kepada pemilik usaha. Metode ini efektif membuat pemilik mengetahui dan memahami pentingnya suatu kinerja dalam menjalankan bisnis untuk jangka waktu yang panjang. Dukungan yang diberikan dalam bentuk penjelasan model penilaian kinerja dalam menjalankan usaha, masalah yang dihadapi, informasi lainnya, bahkan terbuka dengan kelemahan yang mereka hadapi selama ini, sehingga dapat segera dilakukan perbaikan.

FDG dilakukan dengan mensejajarkan posisi mitra dan tim pengabdian masyarakat, sehingga sifatnya berupa sharing informasi. Hal ini dilakukan karena mereka sangat menguasai lapangan selama bertahun tahun dalam menjalankan usaha. Dengan berbagai cara atau strategi yang dapat berbeda satu dengan lainnya. Untuk itu keterlibatan tim PKM sangatlah diperlukan. Model pendampingan penilaian kinerja IKM yang direncanakan bertujuan untuk membantu atau mendorong agar IKM dapat mengetahui posisi kinerja usaha yang sudah tercapai. Apakah sudah memiliki kinerja yang baik/belum. Faktor apa saja yang harus diperbaiki dalam menghadapi kondisi persaingan yang semakin tajam. Selain itu pemilik usaha IKM dapat mengetahui produk apa yang memberikan nilai tambah bagi usahanya. Hal tersebut membantu IKM dalam mendapatkan keuntungan. Proses FDG dilakukan juga pada pembuatan penilaian kinerja di usaha IKM, terkait dengan: penilaian aspek internal, eksternal. Hasil dokumentasi saat pelatihan dan pendampingan secara daring melalui zoom kepada mitra terlihat pada Gambar 4. 


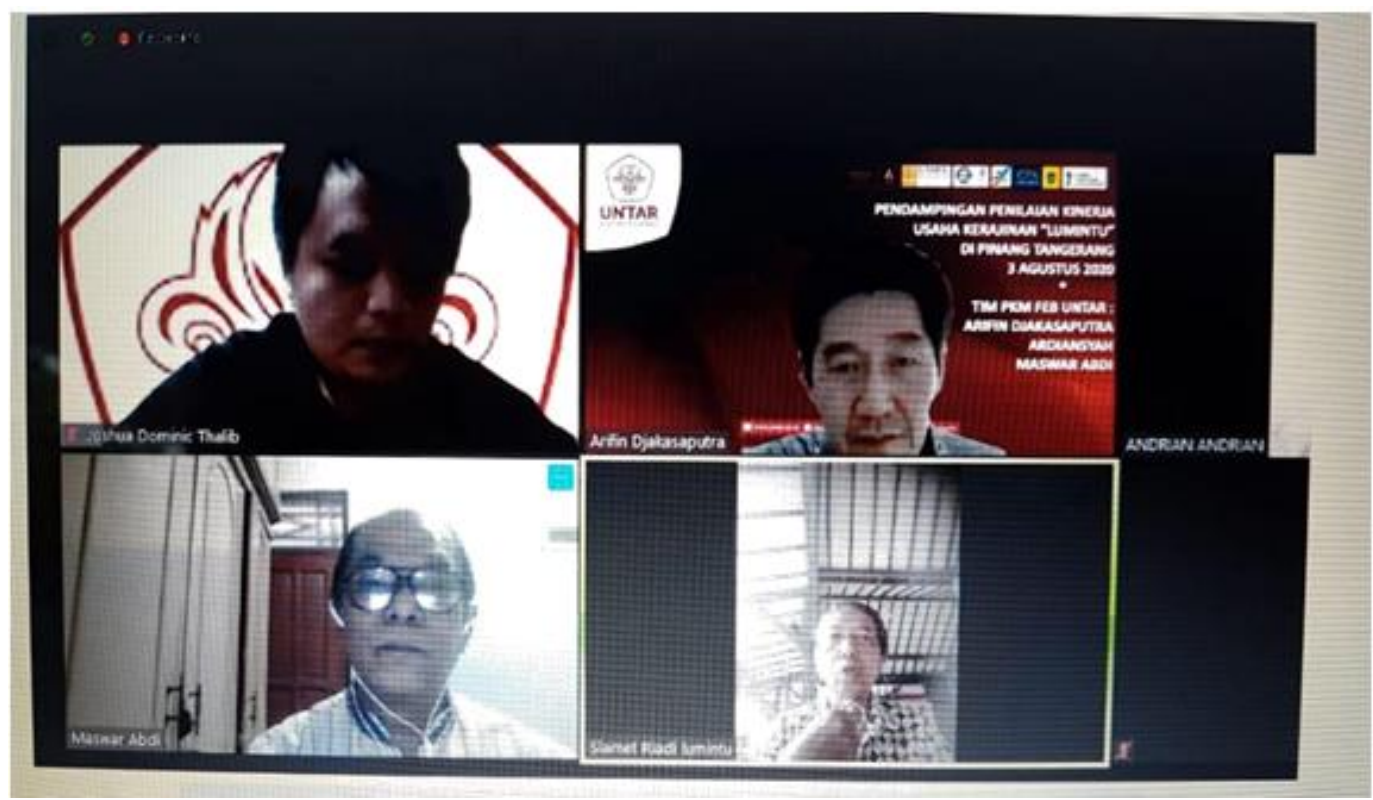

Gambar 4. Sosialisasi Secara Daring

\section{Pendampingan}

Proses pendampingan dilakukan dengan menilai model penilaian faktor Internal dan faktor Eksternal yang sudah dan belum memenuhi bagi usaha Lumintu tertara pada Tabel 1 dan Tabel 2.

Tabel 1. Penilaian Faktor Internal

\begin{tabular}{rll}
\hline \multicolumn{2}{c}{ Hasil Penilaian faktor internal } & Memenuhi / kurang/ tidak \\
\hline Aspek Sumber daya manuasia & $\mathrm{K}$ \\
\hline 1. & Tingkat pendidikan Pemilik & $\mathrm{M}$ \\
\hline 2. & Tingkat Pendidikan Karyawan & $\mathrm{M}$ \\
\hline 3. & Jiwa kepemimpinan & $\mathrm{M}$ \\
\hline 4. & Pengalaman & $\mathrm{M}$ \\
\hline 5. & Lama Usaha & $\mathrm{K}$ \\
\hline 6. & Motivasi pengayam & $\mathrm{M}$ \\
\hline 7. & Keterampilan &
\end{tabular}

\section{Aspek Keuangan :}

\begin{tabular}{llc}
\hline 1. & Modal sendiri & $\mathrm{K}$ \\
\hline 2. & Modal Pinjaman & $\mathrm{T}$ \\
\hline 3. & Tingkat keuntungan & $\mathrm{M}$ \\
\hline 4. & Membedakan pengeluaran pribadi/keluarga & $\mathrm{M}$
\end{tabular}

\section{Aspek teknis dan Operasional}

\begin{tabular}{rll}
\hline 1. & Tersedianya persediaan barang & $\mathrm{M}$ \\
\hline 2. & Kapasitas produksi & $\mathrm{M}$ \\
\hline 3. & Tersedianya mesin/peralatan & $\mathrm{M}$ \\
\hline Aspek pasar dan Pemasaran & $\mathrm{M}$ \\
\hline 1. & Permintaan pasar & $\mathrm{M}$ \\
\hline 2. & Penetapan harga bersaing & $\mathrm{M}$ \\
\hline 3. & Kegiatan promosi & $\mathrm{M}$ \\
\hline 4. & Saluran distribusi & $\mathrm{M}$ \\
\hline 5. & wilayah pemasaran
\end{tabular}


Tabel 2. Penilaian Faktor Eksternal

\begin{tabular}{|c|c|}
\hline Faktor Pemerintah/ Dinas Peridustrian & Memenuhi/Kurang/tidak \\
\hline 1. Kunjungan dari pemerintah Rutin & $\mathrm{M}$ \\
\hline 2. Memberikan penghargaan usaha & $\mathrm{M}$ \\
\hline 3. Memantau kebijakan yang diberikan & $\mathrm{M}$ \\
\hline 4. Memantau kebersihan lingkunan usaha & $\mathrm{M}$ \\
\hline 5. Komunikatif dengan pemilik /pengurus & $\mathrm{M}$ \\
\hline 6. Dinas perindustrian Membantu memecahkan & $\mathrm{M}$ \\
\hline \multicolumn{2}{|l|}{ pesoalan usaha } \\
\hline 7. Kerja sama yang proaktif dengan & $\mathrm{M}$ \\
\hline \multicolumn{2}{|l|}{ mengembangkan usaha } \\
\hline Pemantauan Pemerintah Setempat & Memenuhi/Kurang/tidak \\
\hline 1. Dukungan RT/RW/ Warga & $\mathrm{M}$ \\
\hline 2. Informasi Lingkungan sekitar tentang mengikuti & M \\
\hline \multicolumn{2}{|l|}{ pameran } \\
\hline 3. Kerja sama yang saling menguntungkan dengan & M \\
\hline \multicolumn{2}{|l|}{ warga sekitar } \\
\hline 4. Komunikatif dengan warga & $\mathrm{M}$ \\
\hline 5. Rutinitas mengadakan event dari pemerintah & $\mathrm{M}$ \\
\hline Pengadaan bahan / Supplier Bahan & $\mathrm{M}$ \\
\hline 1. Frekuensi pengiriman bahan baku & $\mathrm{M}$ \\
\hline 2. Rutinitas pengadaan persediaan & $\mathrm{M}$ \\
\hline 3. Fleksibilitas harga dengan pabrik /pemulung/ & M \\
\hline \multicolumn{2}{|l|}{$\begin{array}{l}\text { 3. Fleksibilitas harga dengan pabrik /pemulung/ } \\
\text { penyedia bahan baku }\end{array}$} \\
\hline 4. Rutinitas pembayaran perbulan/ minggu & $\mathrm{M}$ \\
\hline 5. Ketersediaan bahan baku selalu ada & $\mathrm{M}$ \\
\hline 6. Menjalin kerja sama yang baik dengan pabrik & $\mathrm{M}$ \\
\hline Pesaing & $\mathrm{M}$ \\
\hline 1. Jumlah Pesaing cukup banyak & $\mathrm{T}$ \\
\hline 2. Daya tarik pesaing lebih bagus & $\mathrm{T}$ \\
\hline 3. Harga pesaing lebih murah & $\mathrm{T}$ \\
\hline 4. Kualitas pesaing & $\mathrm{T}$ \\
\hline 5. Sumber daya pesaing lebih memadai & $\mathrm{M}$ \\
\hline 6. Pelayanan pesaing lebih baik & $\mathrm{T}$ \\
\hline 7. Keunggulan pesaing & $\mathrm{T}$ \\
\hline \multicolumn{2}{|l|}{ Konsumen } \\
\hline Dapat memenuhi keinginan pelanggan & $\mathrm{K}$ \\
\hline Pelanggan mendapat pelayanan dengan baik & $\mathrm{M}$ \\
\hline dan ramah, & \\
\hline Pelanggan akan merasa puas akan produk & $\mathrm{M}$ \\
\hline yang dibeli & \\
\hline \multicolumn{2}{|l|}{ Kondisi Pengusaha } \\
\hline 1. Selalu melakukan inovasi & M \\
\hline 2. Antisipasi terhadap pesaing & $\mathrm{M}$ \\
\hline 3. Berorientasi pada hasil yang maksimal & $\mathrm{M}$ \\
\hline
\end{tabular}

\section{KESIMPULAN DAN SARAN}

Berdasarkan pelaksanaan kegiatan ini, diperoleh simpulan sementara sebagai berikut:

1. Panduan strategi penilaian kinerja IKM sudah tersusun dengan melakukan FGD, observasi dan wawancara dengan pihak terkait.

2. Sosialisasi secara daring sudah dilakukan pada pemilik usaha Lumintu yang terdapat di kecamatan Sudimara Pinang kota Tangerang. 
3. Model pendampingan dilakukan dalam memberikan penilaian kinerja baik kinerja internal, maupun kinerja eksternal.

4. Secara keseluruhan kinerja usaha dinilai cukup. Ada beberapa hal yang harus diperbaiki seperti pada kinerja internal di aspek SDM dan finansial. Karena pengayam kebanyakan para Lansia cukup sulit mempertahankan keberlanjutan melakukan anyaman. Untuk itu harus perlu dimotivasi secara terus menerus. Selain itu perlu adanya penambahan modal karena masih kurang dalam meningkatkan kapasitas produksi .

\section{Saran}

Perbaikan secara berkelanjutan usaha IKM dapat dilakukan antara lain dapat dikembangkan dalam kajian selanjutnya.

1. Proses pembinaan kontinuitas usaha, melalui pemetaan terhadap permasalahan usaha IKM.

2. Seperti permintaan pemilik, supaya dapat memberikan pelatihan lebih lanjut terutama yang menyangkut aspek manajemen dan finansial. Serta aspek movitasi para Lansia untuk tetap bersemangat membuat anyaman.

\section{REFERENSI}

Beal, R.M. (2000).“ Competing Effectively : Environment Scanning, Competitive Strategy \& Organization Performance in Small Manufacturing Firms" Journal of Small Business Management (Januari):pp.27-45

Bititci,U.S.,Carrie,A.S.McDevittandTurner,T.(1997).Integrated Performance Measurement Systems: A Reference Model. Proceeding of IFIP-WG5.7 1997 Working Conference, Switzerlanda: Ascona Ticono-Switzerland

Kaplan. R.,(2005), How The Balanced Scorecard Complements The McKinsey 7-SModel, Strategy \& Leadership

Laitinen, E (1996,) „Framework for small business performance measurement: towards integrated PMS', Paper presented to Vasaa, proceedings of the University of Vasaa.

Levy, Michael and Barton A. Weitz (2012). Retailing Management. New York : McGraw-Hill Companies

Miles, P Morgan., Covin G jefferey., Heeley b Michael (2000), The Relationship Between Environmental Dynamism and Small Firm structure, strategy, and Performance. Journal of Marketing theory and Practice. Pp. 63-74

Munizu, Musran (2010), Pengaruh Faktor-Faktor Eksternal dan Internal Terhadap Kinerja Usaha Mikro dan Kecil (UMK) di Sulawesi Selatan, Jurnal Manajemen dan Kewirausahaan 12, 33-41.

Nandakumar, M.K; Abby Ghobadian \& Nicholas O’Regan. (2010). Bussiness-Level Strategy and Performance : The Moderating Effect of Environment and Structure. Manajement Decision, 48, 6, 907-939

Neely , A., (1999), The Performance Measurement Revolution: Why Now and What Next? International Journal of Operations \& Production Management, Vol. 19 No. 2,pp. 205-228

Rodhiah dan Zahrida Wiryawan (2016). Internal Performance Measurement Model for Small Retailers. Proceeding The First International Conference on Education ICONLEE 2016

Zahra, S.A., dan S. R. Das (1993), Innovation Strategy and Financial Performance in manufacturing companies: An empirical Study. Production and OperationsManagement 2 (I) (Winter) : 15-37 